\title{
Jenis-jenis Jamur Makroskopis di Pulau Kemujan, Taman Nasional Karimunjawa
}

\section{Types of Macroscopic Fungi on Kemujan Island, Karimunjawa National Park}

\section{Limaryadi ${ }^{1}$, Sumaryati $S^{1}$}

${ }^{1}$ Balai Taman Nasional Karimunjawa, Jl. Sinar Waluyo Raya, No. 248, Semarang 50723, Jawa Tengah, Indonesia

Limaryadi, Sumaryati S. 2021 - Jenis-jenis Jamur Makroskopis di Pulau Kemujan, Taman Nasional Karimunjawa. Jurnal Mikologi Indonesia 5(1): 41-47. doi: 10.46638/jmi.v5i1.168

\begin{abstract}
Abstrak
Taman Nasional Karimunjawa merupakan kawasan konservasi yang terletak di utara Laut Jawa dengan luas kawasan mencapai 111.625 ha. Kawasan ini memiliki tipe ekosistem hutan hujan tropis dataran rendah, pantai, mangrove, terumbu karang, dan lamun. Kepulauan Karimunjawa terdiri dari 27 pulau, dengan lima pulau utama yang dihuni oleh 9784 penduduk. Dikenal sebagai kawasan konservasi perairan, Taman Nasional Karimunjawa memiliki keaneragaman jamur yang patut diperhitungkan. Tujuan dari penelitian ini adalah untuk mengidentifikasi jenis jamur makroskopis yang ada di Pulau Kemujan, Taman Nasional Karimunjawa. Metode yang digunakan dalam penelitian ini adalah survei. Survei melalui eksplorasi dilakukan di Pulau Kemujan yaitu di Legon Jelamun, Legon Gede, Legon Pinggir, Mrican, dan Telogo. Area tersebut merupakan hutan mangrove, vegetasi pantai dan kebun penduduk. Hasil eksplorasi di Pulau Kemujan menemukan 65 jenis dari 24 suku. Jenis dari suku Polyporaceae merupakan jenis yang paling sering dijumpai, dari suku ini teridentifikasi 24 jenis. Jenis dari suku Polyporaceae yang teridentifikasi diantaranya adalah Daedaleopsis confragosa, Lentinus arcularius, Microporus sp. Dari suku Tricholomataceae teridentifikasi empat jenis antara lain Pleurotus ostreatus, dan Collybia cf. cookei. Dari suku Agaricaceae ditemukan lima jenis, suku Ganodermaceae ditemukan tiga jenis, suku Cortinariaceae ditemukan tiga jenis. Jamur ditemukan pada bermacam-macam substrat yaitu tanah, tanah berpasir, serasah, batang pohon mati dan serbuk bekas penggergajian.
\end{abstract}

Kata Kunci: jamur makroskopis - identifikasi - Karimunjawa - taman nasional.

\section{Abstract}

Karimunjawa National Park is a conservation area located north of the Java Sea with 111,625 hectares of area. This area has an ecosystem type of lowland tropical rain forest, beaches, mangroves, coral reefs, and seagrass. Karimunjawa Islands consists of 27 islands, with five main islands inhabited by 9784 residents. This study aimed to identify the types of fungi that exist in Kemujan Island, Karimunjawa National Park. The survey method was used in this research. The survey through exploration was carried out on Kemujan Island. Locations that become observation sites are mangrove forests, coastal vegetation, and community yard. The results of exploration in Kemujan Island found 65 species from 25 families. The type of the Polyporaceae family is the type most often found, 24 species of this family were identified. The identified types of the Polyporaceae family include Daedaleopsis confragosa, Lentinus arcularius, Microporus sp. From the Tricholomataceae family, four types were identified Pleurotus ostreatus, Collybia cf. cookei. Five species were found from the Agaricaceae family, three types were found in the Ganodermataceae family, three in the Cortinariaceae family. Fungi are found in various substrates: soil, sandy soil, litter, dead tree trunks, and sawdust.

Keywords: identification - Karimunjawa-macroscopic fungi-national park. 


\section{Pendahuluan}

Kepulauan Karimunjawa terdiri dari 27 pulau yang terbentang di perairan utara Laut Jawa. Kepulauan ini secara administratif adalah Kecamatan Karimunjawa bagian dari Kabupaten Jepara, Provinsi Jawa Tengah. Kecamatan Karimunjawa terdiri dari empat desa yaitu Desa Parang, Desa Nyamuk, Desa Kemujan dan Desa Karimunjawa. Populasi penduduk mencapai 9784 jiwa mendiami lima pulau utama yaitu Pulau Karimunjawa, Pulau Kemujan, Pulau Parang, Pulau Nyamuk, dan Pulau Genting. Pulau Kemujan secara administratif merupakan salah satu desa di Kecamatan Karimunjawa. Desa Kemujan memiliki luas 1626 Hektar (BPS Kabupaten Jepara, 2020). Beberapa area di Desa Kemujan merupakan bagian dari kawasan konservasi Taman Nasional Karimunjawa. Hutan Mangrove yang berada di Desa Kemujan merupakan zona perlindungan dan zona pemanfaatan dari Taman Nasional Karimunjawa. Sebagian besar area di Kepulauan Karimunjawa merupakan Taman Nasional Karimunjawa. Luas kawasan konservasi perairan ini mencapai 111.625 ha. Perairan Karimunjawa berawal dari status cagar alam yang selanjutnya diubah menjadi kawasan konservasi dengan bentuk taman nasional (Balai Taman Nasional Karimunjawa, 2020). Taman Nasional Karimunjawa memiliki lima tipe ekosistem yaitu, ekosistem terumbu karang, lamun, pantai, mangrove dan hutan hujan tropis dataran rendah. Kelima tipe ekosistem ini yang menjadikan Taman Nasional Karimunjawa menjadi kawasan yang menarik untuk dieksplorasi.

Lebih dikenal sebagai kawasan konservasi perairan, Taman Nasional Karimunjawa masih menyimpan berbagai jenis flora dan fauna yang dapat dipelajari. Salah satunya adalah jamur makroskopis. Jamur memiliki peran dalam ekosistem untuk melakukan dekomposisi bahan-bahan organik di dalam tanah. Proses pembusukan dapat terakselerasi dengan kehadiran jamur. Di tahun 2018, jamur makroskopis yang teridentifikasi sejumlah 32 jenis, pada tahun 2020 terdapat penambahan sejumlah 79 jenis, sehingga saat ini di Taman Nasional Karimunjawa tercatat 111 jenis jamur (Balai Taman Nasional Karimunjawa, 2020). Identifikasi jenis jamur makroskopis di tahun 2018 dilakukan pada kawasan berupa ekosistem hutan hujan tropis dataran rendah yang terletak di Pulau Karimunjawa. Penambahan jenis masih dimungkinkan mengingat pengamatan yang dilakukan belum mencakup ekosistem mangrove dan hutan pantai. Pulau Kemujan merupakan salah satu pulau yang terdapat di Kepulauan Karimunjawa dan memiliki ekosistem mangrove. Hal ini mendorong untuk dilakukan identifikasi terhadap jenis jamur makroskopis di pulau tersebut sehingga keanekaragaman jenis jamur makroskopis bertambah. Tujuan dari penelitian ini adalah untuk mengetahui jenis jamur yang ada di Pulau Kemujan, Taman Nasional Karimunjawa.

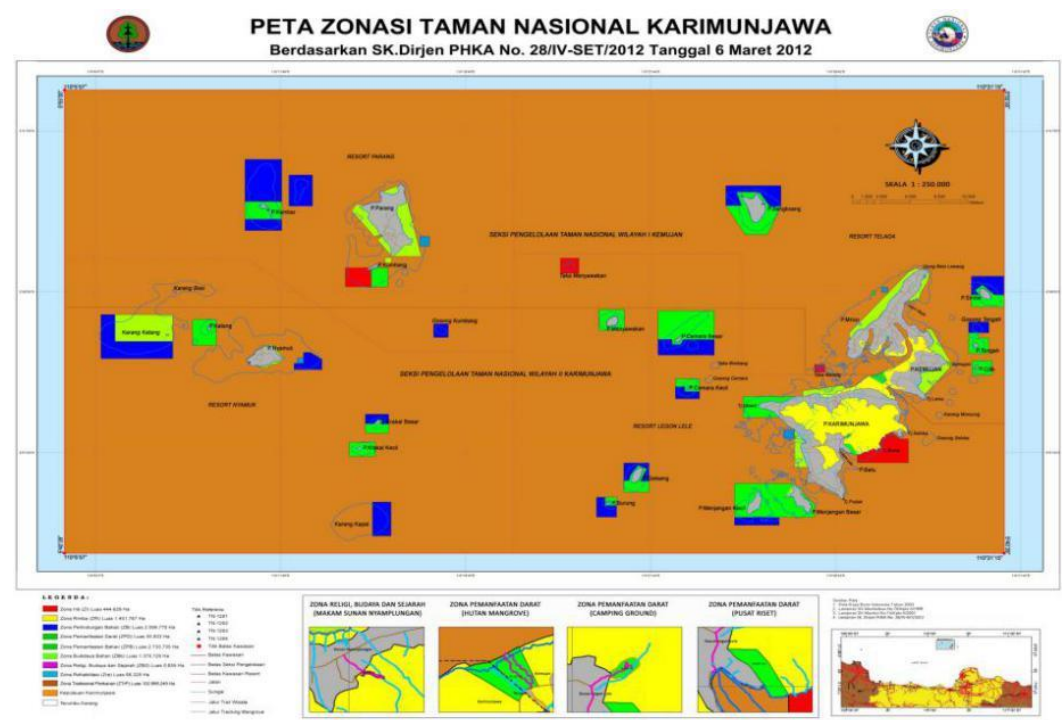

Gambar 1. Peta Zonasi Taman Nasional Karimunjawa 


\section{Metode Penelitian}

Penelitian ini menggunakan metode survei dengan teknik eksplorasi. Pengamatan dilakukan dengan menyusuri area hutan mangrove, sekitar hutan mangrove dan kebun penduduk yang berada di Pulau Kemujan. Pemilihan lokasi dilakukan secara acak dengan melakukan penyusuran di area Legon Jelamun, Legon Pinggir, Legon Gede, Batu Lawang, Telogo, dan Mrican. Jamur yang dijumpai didokumentasikan bagian atas, bawah dan keseluruhan jamur. Bentuk, ukuran dan warna jamur juga diamati, untuk identifikasi dilakukan dengan menggunakan beberapa buku identifikasi jamur Knight \& Knight (1987) dan Catatan Komunitas Pemburu Jamur Indonesia oleh Ivan Permana Putra dan Khalid Hafazallah. Menurut Putra dan Hafazallah (2020), jenis jamur yang terdapat di buku tersebut divalidasi posisi taksonominya dengan mengacu pada Index Fungorum. Informasi lain yang dicatat saat menjumpai jamur adalah lokasi, substrat tempat hidup dan waktu temuan.

\section{Hasil}

Dari hasil pengamatan di lapangan teridentifikasi 65 jenis jamur dari 24 suku dan 1 bangsa Agaricales (Incertae sedis) (Tabel 1), yaitu Agaricaceae, Amanitaceae, Auriculariaceae, Boletaceae, Cantharellaceae, Clavariaceae, Cortinariaceae, Dacrymycetaceae, Fomitopsidaceae, Ganodermataceae, Gomphaceae, Hygrophoraceae, Hypoxylaceae, Lyophyllaceae, Marasmiaceae, Omphalotaceae, Phallaceae, Polyporaceae, Psathyrellaceae, Russulaceae, Tremellaceae, Tricholomataceae, dan Xylariaceae. Jenis dari suku Polyporaceae yang teridentifikasi diantaranya adalah Daedaleopsis confragosa, Lentinus arcularius, Hexagonia tenuis. Dari suku Tricholomataceae teridentifikasi empat jenis antara lain Pleurotus sp., Pleurotus ostreatus, dan Collybia cf. cookei. Dari suku Agaricaceae ditemukan lima jenis antara lain Agaricus cf. arvensis, Agaricus trisulphuratus. Dari suku Ganodermataceae ditemukan tiga jenis yaitu Ganoderma sp., Ganoderma tsugae, Amauroderma sp. Dari suku Cortinariaceae ditemukan tiga jenis, dari suku Auriculariaceae, Boletaceae, masing-masing ditemukan dua jenis. Lima belas suku lainnya ditemukan masingmasing satu jenis.

Secara umum jamur ditemukan dalam tiga jenis substrat yaitu tanah, serasah dan batang pohon. Pada area Legon Jelamun, jamur dijumpai pada substrat tanah, tanah berpasir, tanah berkerikil, tanah yang disekitarnya terdapat serasah. Jamur yang dijumpai di Legon Pinggir ditemukan berada pada substrat tanah berlumpur, area ini merupakan hutan mangrove yang berada dalam kawasan Taman Nasional Karimunjawa. Jamur dari jenis Marasmius haematocephalus ditemukan pada serasah di area Legon Jelamun. Sebagian besar jamur atau sekitar 68\% jamur ditemukan pada substrat berupa kayu yang lapuk. Terdapat beberapa pohon yang masih dapat dikenali jenis kayu yang dijadikan tempat menempel jamur diantaranya batang pohon kersen (Muntingia calabura), batang pohon kelapa (Cocos nucifera), batang pohon laban (Vitex pubescens), dan batang pohon mete (Anacardium occidentale). Di area Legon Jelamun, jamur Panaeolus sp. ditemukan pada kotoran sapi kering dan jamur Tricholomopsis sp. ditemukan pada serbuk bekas penggergajian. 

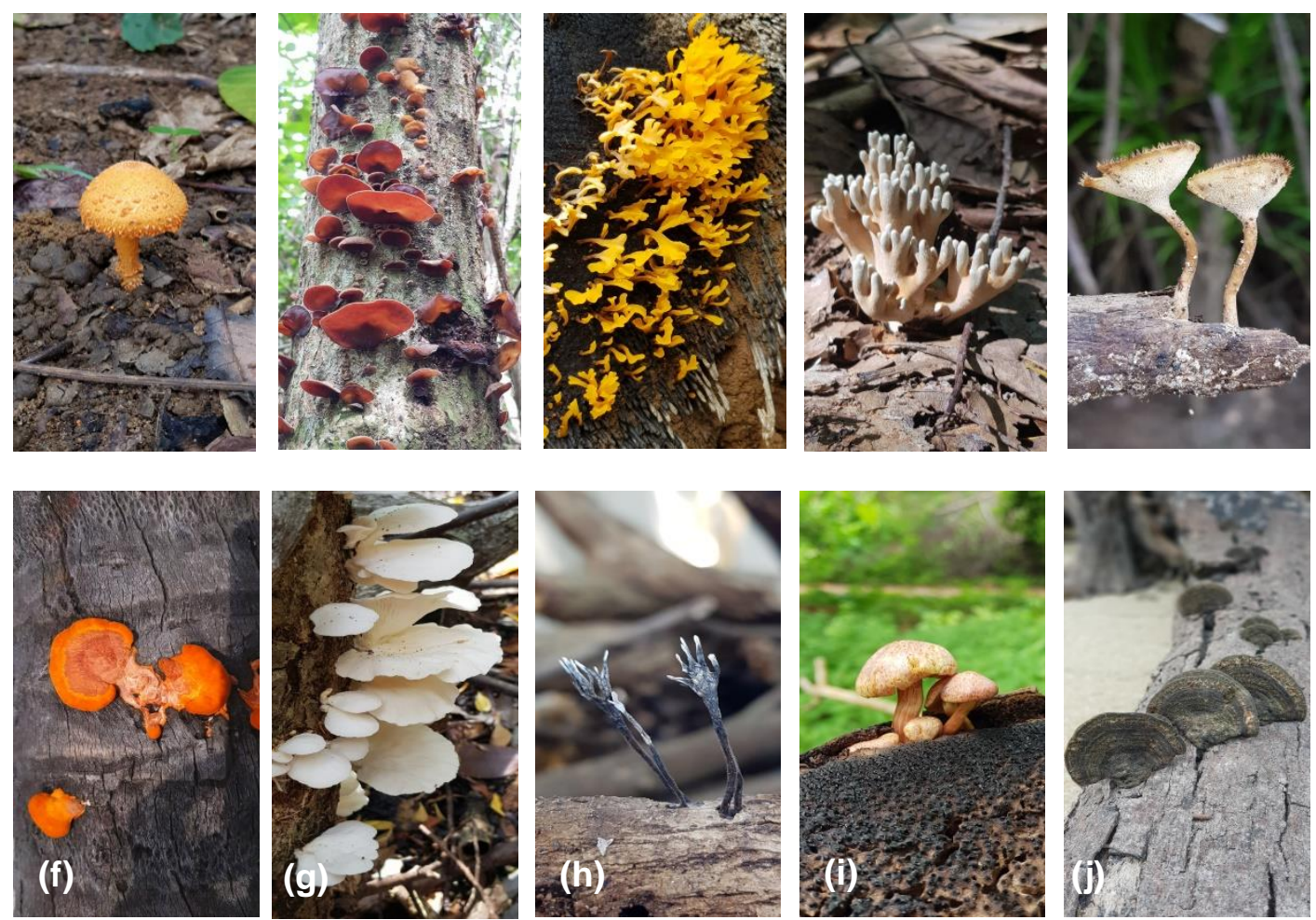

Gambar 2. Jenis jamur yang dijumpai di Pulau Kemujan: (a) Agaricus trisulphuratus, (b) Auricularia auricula-judae, (c) Dacryopinax spathularia, (d) Ramaria cf. zippelii, (e) Lentinus arcularius (f) Pycnoporus cinnabarinus, (g) Pleurotus ostreatus, (h) Xylaria hypoxylon, (i) Gymnopilus lepidotus, (j) Hexagonia hydnoides.

Tabel 1. Daftar jenis jamur yang teridentifikasi di Pulau Kemujan

\begin{tabular}{|c|c|c|c|c|}
\hline No & Suku & Jenis & Substrat & Lokasi \\
\hline 1 & Agaricaceae & Agaricus cf. arvensis & Tanah berpasir dan kerikil & Legon Jelamun \\
\hline 2 & Agaricaceae & Agaricus sp. 1 & Tanah & Legon Jelamun \\
\hline 3 & Agaricaceae & Agaricus sp. 2 & Tanah, sekitar berserasah & Legon Jelamun \\
\hline 4 & Agaricaceae & Agaricus sp. 3 & Tanah berlumpur & $\begin{array}{l}\text { Legon Pinggir } \\
\text { (kawasan mangrove) }\end{array}$ \\
\hline 5 & Agaricaceae & Agaricus trisulphuratus & Tanah, sekitar berserasah & Legon Jelamun \\
\hline 6 & Amanitaceae & Amanita sp. & Tanah, sekitar berserasah & Legon Jelamun \\
\hline 7 & Auriculariaceae & Auricularia auricula-judae & Batang pohon mati & $\begin{array}{l}\text { Legon gede (kawasan } \\
\text { mangrove) }\end{array}$ \\
\hline 8 & Auriculariaceae & Auricularia mesenterica & $\begin{array}{l}\text { Batang pohon kersen } \\
\text { (Muntingia calabura) mati. }\end{array}$ & Kemujan \\
\hline 9 & Boletaceae & Boletus sp. & Kayu bulat mati & Legon gede \\
\hline 10 & Boletaceae & Gyrodontium sacchari & Batang pohon kelapa mati. & Legon Pinggir \\
\hline 11 & Cantharellaceae & Cantharellus sp. & Tanah & Legon Pinggir \\
\hline 12 & Clavariaceae & Clavaria fragilis & Tanah dan kayu mati & $\begin{array}{l}\text { Legon Pinggir, Mrican } \\
\text { dan Legon Jelamun }\end{array}$ \\
\hline 13 & Cortinariaceae & Cortinarius austroalbidus & Tanah, sekitar berserasah & Kemujan \\
\hline 14 & Cortinariaceae & Gymnopilus lepidotus & $\begin{array}{l}\text { Bongkahan dan kulit papan } \\
\text { pohon kelapa }\end{array}$ & Kemujan \\
\hline 15 & Cortinariaceae & Gymnopilus sp. & Kayu mati & Legon gede \\
\hline 16 & Dacrymycetaceae & Dacryopinax spathularia & $\begin{array}{l}\text { bongkahan pohon kelapa } \\
\text { mati dan kayu mati }\end{array}$ & $\begin{array}{l}\text { Legon gede, Legon } \\
\text { Jelamun }\end{array}$ \\
\hline
\end{tabular}




\begin{tabular}{|c|c|c|c|c|}
\hline No & Suku & Jenis & Substrat & Lokasi \\
\hline 17 & Fomitopsidaceae & Daedalea quercina & $\begin{array}{l}\text { Kayu mati (kawasan } \\
\text { mangrove) }\end{array}$ & Legon Jelamun \\
\hline 18 & Ganodermataceae & Ganoderma sp. & Kayu mati & $\begin{array}{l}\text { Legon jelamun, } \\
\text { Kemujan }\end{array}$ \\
\hline 19 & Ganodermataceae & Ganoderma tsugae & $\begin{array}{l}\text { bongkahan pohon bekas } \\
\text { bakar }\end{array}$ & Kemujan \\
\hline 20 & Ganodermataceae & Amauroderma sp. & Tanah, sekitar berserasah & Legon Pinggir \\
\hline 21 & Gomphaceae & Ramaria cf. zippelii & Tanah, sekitar berserasah & $\begin{array}{l}\text { Legon Jelamun, Legon } \\
\text { Pinggir }\end{array}$ \\
\hline 22 & Hygrophoraceae & Hygrocybe sp. & Tanah, sekitar berserasah & Legon Jelamun \\
\hline 23 & Hypoxylaceae & Daldinia concentrica & Kayu mati & $\begin{array}{l}\text { Legon Gede, } \\
\text { Batulawang }\end{array}$ \\
\hline 24 & $\begin{array}{l}\text { Agaricales } \\
\text { (Incertae sedis) }\end{array}$ & Panaeolus sp. & Kotoran sapi kering & Legon Jelamun \\
\hline 25 & Lyophyllaceae & Rugosomyces ionides & Tanah, dekat rumah rayap & Legon Gede \\
\hline 26 & Lyophyllaceae & Termitomyces sp. & $\begin{array}{l}\text { Tanah, sekitar serasah dan } \\
\text { ternaungi }\end{array}$ & $\begin{array}{l}\text { Legon Jelamun, Legon } \\
\text { Gede, Batulawang }\end{array}$ \\
\hline 27 & Lyophyllaceae & Termitomyces microcarpus & Tanah, sekitar berserasah & Legon Jelamun \\
\hline 28 & Marasmiaceae & Gymnopus sp. & $\begin{array}{l}\text { Tanah, sekitar berserasah } \\
\text { dan berumput }\end{array}$ & Kemujan \\
\hline 29 & Marasmiaceae & Marasmius haematocephalus & Serasah & Legon Jelamun \\
\hline 30 & Marasmiaceae & Lactocollybia sp. & Kayu mati & Mrican \\
\hline 31 & Omphalotaceae & Anthracophyllum archeri & Kayu mati & Kemujan \\
\hline 32 & Phallaceae & Phallus indusiatus & Tanah & $\begin{array}{l}\text { Legon Jelamun, } \\
\text { Kemujan }\end{array}$ \\
\hline 33 & Polyporaceae & Daedalopsis confragosa & Kayu mati batang mangrove & Kemujan \\
\hline 34 & Polyporaceae & Favolus alveolaris & Kayu mati batang mangrove & Legon Jelamun \\
\hline 35 & Polyporaceae & Favolus sp. & Kayu mati batang mangrove & Legon Jelamun \\
\hline 36 & Polyporaceae & Hexagonia hydnoides & Kayu mati & Legon Jelamun \\
\hline 37 & Polyporaceae & Hexagonia nitida & Kayu mati batang mangrove & $\begin{array}{l}\text { Kemujan, Legon } \\
\text { Jelamun }\end{array}$ \\
\hline 38 & Polyporaceae & Hexagonia tenuis & Kayu mati & $\begin{array}{l}\text { Kemujan, Legon } \\
\text { Jelamun }\end{array}$ \\
\hline 39 & Polyporaceae & Lentinus arcularius & Kayu mati & $\begin{array}{l}\text { Legon Jelamun, Legon } \\
\text { Gede }\end{array}$ \\
\hline 40 & Polyporaceae & Lentinus concavus & Kayu mati & Kemujan \\
\hline 41 & Polyporaceae & Lentinus sajor-caju & Kayu mati & $\begin{array}{l}\text { Legon Jelamun, Legon } \\
\text { Pinggir Kawasan } \\
\text { mangrove) }\end{array}$ \\
\hline 42 & Polyporaceae & Lentinus sp. & Kayu mati & Legon Pinggir \\
\hline 43 & Polyporaceae & Lentinus squarrosulus & $\begin{array}{l}\text { Kayu mati batang pohon } \\
\text { mete }\end{array}$ & Telogo \\
\hline 44 & Polyporaceae & Lentinus tigrinus & $\begin{array}{l}\text { Batang bekas tebangan dan } \\
\text { terbakar (kayu mati) }\end{array}$ & Telogo \\
\hline 45 & Polyporaceae & Lentinus tricholoma & $\begin{array}{l}\text { Kayu mati (kawasan } \\
\text { mangrove) }\end{array}$ & Legon Jelamun \\
\hline 46 & Polyporaceae & Lentinus tuber-regium & Kayu mati & Legon Jelamun \\
\hline 47 & Polyporaceae & Lenzites betulinus & $\begin{array}{l}\text { Kayu mati (kawasan } \\
\text { mangrove) }\end{array}$ & Kemujan \\
\hline
\end{tabular}




\begin{tabular}{|c|c|c|c|c|}
\hline No & Suku & Jenis & Substrat & Lokasi \\
\hline 48 & Polyporaceae & Microporus sp. & Kayu mati & Legon Pinggir \\
\hline 49 & Polyporaceae & Polyporus badius & $\begin{array}{l}\text { Kayu mati (kawasan } \\
\text { mangrove) }\end{array}$ & Kemujan \\
\hline 50 & Polyporaceae & Pycnoporus cinnabarinus & $\begin{array}{l}\text { Kayu mati (belahan pohon } \\
\text { kelapa) }\end{array}$ & Legon Jelamun \\
\hline 51 & Polyporaceae & Trametes sp. 2 & Kayu mati & $\begin{array}{l}\text { Legon Jelamun, } \\
\text { Kemujan }\end{array}$ \\
\hline 52 & Polyporaceae & Trametes sp. 3 & kayu mati & Legon Pinggir \\
\hline 53 & Polyporaceae & Trametes gibbosa & $\begin{array}{l}\text { Kayu bulat mati (batang } \\
\text { pohon walangan) }\end{array}$ & Legon Jelamun \\
\hline 54 & Polyporaceae & Trametes hirsuta & Kayu mati & Legon Jelamun \\
\hline 55 & Polyporaceae & Trametes villosa & Kayu mati (bongkahan kayu) & Legon Jelamun \\
\hline 56 & Polyporaceae & Trametes sp. 1 & $\begin{array}{l}\text { Kayu mati (kawasan } \\
\text { mangrove) }\end{array}$ & $\begin{array}{l}\text { Legon Pinggir, } \\
\text { Kemujan }\end{array}$ \\
\hline 57 & Psathyrellaceae & Psathyrella cf. cernua & Kayu mati, pohon kelapa & Legon Jelamun \\
\hline 58 & Psathyrellaceae & Psathyrella candolleana & Kayu mati & Legon jelamun \\
\hline 59 & Russulaceae & Lactarius sp. & Tanah, sekitar berserasah & Legon Gede \\
\hline 60 & Tremellaceae & Tremella fuciformis & Kayu mati & $\begin{array}{l}\text { Batulawang, Legon } \\
\text { Gede, Legon Jelamun }\end{array}$ \\
\hline 61 & Tricholomataceae & Collybia cf. cookei & $\begin{array}{l}\text { Tanah berpasir, dan bekas } \\
\text { terbakar }\end{array}$ & Legon Jelamun \\
\hline 62 & Tricholomataceae & Pleurotus sp. & kayu bulat mati, pohon mete & Legon Gede \\
\hline 63 & Tricholomataceae & Pleurotus ostreatus & $\begin{array}{l}\text { Kayu mati, pohon kersen dan } \\
\text { pohon mangrove }\end{array}$ & $\begin{array}{l}\text { Legon Pinggir, } \\
\text { Kemujan }\end{array}$ \\
\hline 64 & Tricholomataceae & Tricholomopsis sp. & $\begin{array}{l}\text { Serbuk/serutan bekas } \\
\text { gergajian }\end{array}$ & Legon Jelamun \\
\hline 65 & Xylariaceae & Xylaria hypoxylon & $\begin{array}{l}\text { Kayu mati dan kulit kayu yg } \\
\text { mengelupas pada pohon } \\
\text { laban yang masih tumbuh }\end{array}$ & Legon Jelamun \\
\hline
\end{tabular}

\section{Pembahasan}

Jamur ditemukan pada substrat pohon mati, serasah daun dan tanah. Substrat ini merupakan substrat yang sesuai dengan pertumbuhan jamur. Menurut Rahmawati (2018), jamur makroskopis tersebut ada yang tumbuh pada substrat daun mati, pohon mati dan tanah, hal ini dikarenakan substrat tersebut merupakan substrat yang cocok untuk pertumbuhan jamur. Suku Agaricaceae, Gomphaceae, Lyophyllaceae, Phallaceae, dan Russulaceae ditemukan pada substrat tanah. Suku tersebut dijumpai pada tanah yang disekelilingnya merupakan tanah berpasir, kerikil dan serasah mangrove. Suku Clavariaceae dan Tricholomataceae dapat ditemukan pada substrat tanah maupun kayu mati. Suku Polyporaceae, Psathyrellaceae, Tremellaceae dijumpai pada substrat berupa kayu mati yang berada dalam area hutan mangrove. Jenis Tricholomopsis sp. ditemukan di luar hutan mangrove yaitu disekitar pemukiman penduduk. Lokasi pengamatan di Telogo, Legon Jelamun, Legon Pinggir, Legon Gede memiliki kesamaan berupa hutan mangrove. Jamur yang dijumpai di area tersebut menempel pada kayu lapuk. Identifikasi terhadap jenis pohon yang menjadi tempat menempel jamur sulit dilakukan karena kayu pohon sudah lapuk. Lokasi pengamatan di Batu Lawang dan Kemujan berupa kebun atau pekarangan penduduk. Dari sebaran lokasi, menunjukkan bahwa sebagian besar lokasi pengamatan merupakan hutan mangrove. Jenis jamur yang dijumpai di hutan mangrove dapat juga dijumpai di luar area yang tidak memiliki vegetasi mangrove. Jamur makroskopis pada umumnya hidup sebagai 
saprofit, dan memiliki peran sebagai pengurai bahan-bahan organik mati seperti kayu mati atau kayu lapuk dan serasah. Keanekaragaman vegetasi yang terdapat di Taman Nasional Karimunjawa dapat memberikan ketersediaan substrat bagi pertumbuhan jamur. Setiap jenis jamur memiliki kemampuan adaptasi yang berbeda pada suatu habitat. Annissa dkk. (2017) melaporkan jamur makroskopis dari Arboretum Sylva, Universitas Tanjung Pura di Kalimantan Barat, dari luasan 0,0625 ha tercatat 30 jenis dari total 1.652 individu terdiri dari 21 marga dan 12 suku yang terdiri atas Polyporaceae, Ganodermataceae, Rigidoporaceae, Cortinariaceae, Auriculariaceae, Coprinaceae, Sclerodermataceae, Agaricaceae, Schizophyllaceae, Phallaceae, dan Geastraceae.

Jamur dari suku Polyporaceae merupakan jenis yang paling sering dijumpai, terdapat 24 jenis jamur yang teridentifikasi dari suku Polyporaceae. Jamur ini dapat tumbuh pada dataran kurang dari $1000 \mathrm{dpl}$, dengan curah hujan 2000-2500mm/tahun (Lestari \& Febrianti, 2018). Berdasarkan klasifikasi tipe iklim Schmidt dan Ferguson, kawasan Taman Nasional Karimunjawa termasuk tipe $\mathrm{C}$ dengan rata-rata curah hujan $3.000 \mathrm{~mm} / \mathrm{tahun}$, sedangkan temperatur udara berkisar antara $30^{\circ}-31^{\circ} \mathrm{C}$ (Balai Taman Nasional Karimunjawa, 2018). Suku Polyporaceae memiliki tubuh buah yang besar sehingga memiliki kemampuan untuk beradaptasi dengan baik di berbagai lingkungan. Jamur dari suku Polyporaceae mampu bertahan hidup pada kondisi yang kering, dapat tumbuh pada kayu mati dengan kandungan air yang sedikit. Karakteristik dari suku ini adalah tubuh buah yang berupa kipas, himenifora merupakan buluh-buluh (Lestari \& Febrianti, 2018).

Faktor yang mempengaruhi pertumbuhan jamur adalah ketersediaan nutrisi karena pelapukan dan kondisi lingkungan (Prasetyaningsih \& Raharjo, 2015). Kayu lapuk berfungsi sebagai penyedia nutrisi yang cukup bagi jamur. Jamur yang ditemukan menempel pada kayu lapuk di dalam hutan mangrove menunjukkan bahwa hutan mangrove juga berpotensi sebagai penyedia nutrisi bagi jamur. Kemampuan jamur untuk beradaptasi bukan jaminan bahwa jenis jamur di alam tidak terancam keberadaannya. Ancaman keanekaragaman jamur sebagian besar disebabkan oleh kerusakan habitat, perubahan iklim atau aktivitas penebangan (Prasetyaningsih \& Raharjo, 2015).

Enam puluh lima jenis yang teridentifikasi di Pulau Kemujan, menambahkan keanekaragaman jenis jamur di Taman Nasional Karimunjawa. Peluang penambahan jenis jamur di kawasan konservasi ini masih dimungkinkan, mengingat luasnya area yang masih belum di eksplorasi. Diperlukan penelitian lebih lanjut tentang keanekaragaman, kelimpahan, potensi, dan sebaran jamur di Taman Nasional Karimunjawa.

Berdasarkan hasil eksplorasi di Pulau Kemujan, dapat disimpulkan terdapat 65 jenis jamur makroskopis dari 23 suku. Enam puluh lima jenis yang teridentifikasi di Pulau Kemujan, menambahkan keanekaragaman jenis jamur di Taman Nasional Karimunjawa. Jenis dari suku Polyporaceae merupakan jenis yang paling sering dijumpai, dari family ini teridentifikasi 24 jenis. Secara umum jamur ditemukan dalam tiga jenis substrat yaitu tanah, serasah dan batang pohon. Keanekaragaman jenis jamur di Taman Nasional Karimunjawa masih harus digali dengan melakukan survei pada lokasi yang berbeda.

\section{Pustaka}

Annissa, I., Ekamawanti, A. H., \& Wahdina. (2017). Keanekaragaman jenis jamur makroskopis di Arboretum Sylva Universitas Tanjung Pura. Jurnal Hutan Lestari, 5(4). 969-977.

Balai Taman Nasional Karimunjawa. (2018). Rencana Pengelolaan Jangka Panjang Taman Nasional Karimunjawa tahun 2018-2027. Semarang.

Balai Taman Nasional Karimunjawa. (2020). Statistik Balai Taman Nasional Karimunjawa. Semarang: Balai Taman Nasional Karimunjawa. 
BPS Kabupaten Jepara. (2020). Kecamatan Karimunjawa Dalam Angka 2020. Jepara: Badan Pusat Statistik Kabupaten Jepara.

Lestari, F., \& Febrianti, Y. (2018). Identifikasi makrofungi Ordo Polyporales di Kecamatan Purwodadi Kabupaten Musi Rawas. IJOBB, 2(1), 25-29.

McKnight, K.H., \& McKnight, V.B. (1987). A Field Guide to Mushrooms: North America (Peterson Field Guides). Houghton Mifflin Harcourt.

Prasetyaningsih, A., \& Raharjo, J. (2015). Keanekaragaman dan Potensi Makrofungi Taman Nasional Gunung Merapi. The2nd University Research Coloquium, (pp. 471-480).

Putra, I. P. \& Hafazallah, K. (2020). Catatan Komunitas Pemburu Jamur Indonesia. Sukabumi: Haura Publishing.

Rahmawati, L. R. (2018). Jenis-jenis jamur makroskopis anggota Kelas Basidiomycetes di Hutan Bayur, Kabupaten Landak, Kalimantan Barat. Jurnal Mikologi Indonesia, 2(2), $56-65$. 